\title{
An Evaluation of the Anti-Cancerous Effects of Tinospora cordifolia and Aristolochia bracteolate Using CADD (Computer Aided Drug Discovery) Tools
}

\author{
Cecilia Joseph $^{1 *}$, S. Preetha ${ }^{2}$, P.L. Sujatha ${ }^{3^{*}}$, C. Balachandran ${ }^{4}$ and N. Punniamurthy ${ }^{5}$ \\ ${ }^{1}$ Department of Clinics, ${ }^{2}$ Department of Veterinary Pharmacology and Toxicology, \\ ${ }^{4}$ Department of Veterinary Pathology, Madras Veterinary College, \\ Chennai-600 007, Tamil Nadu, India \\ ${ }^{3}$ College of Food and Dairy Technology, Chennai-600 052, Tamil Nadu, India \\ ${ }^{5}$ VUTRC, Thanjavur, Tamil Nadu, India \\ *Corresponding author
}

\section{A B S T R A C T}

\section{Key words \\ Cancer, Tinospora cordifolia and Aristolochia bracteolate, in-silico study \\ Article Info \\ Accepted: \\ 04 March 2018 Available Online: 10 June 2018}

Cancer is an imminent global disaster and the incidence of cancer is widespread in animals with malignant characters and lesions like human beings. Keeping in view the importance and advantages of combination therapy using herbal based natural EVP products on the tumour cells, an attempt to explore the influence of combined effect of Aristolochia bracteolata and Tinospora cordiflora' was analyzed using in silico approach. It was found that the combined effect of Aristolochia bracteolate and Tinospora cordiflora have shown to possess significant anti-proliferative and anti- apoptotic properties. The active principles from both the plants possess significant pharmaco kinetic and pharmacodynamics effects. As they work synergistically, the combined effect may be a promising drug entity to enter the evidence based therapeutics for cancer.

\section{Introduction}

Cancer is a class of disease in which a group of cells display uncontrolled growth, invasion and metastasis. Cancer may affect at all ages, even foetuses, but the risk of most varieties is increasing. Cancer causes about $13 \%$ of all human deaths (Amita Mishra et al., 2013). Natural products have been traditionally accepted as remedies for many diseases. The beneficial effects of plant products typically result from the combinations of secondary metabolities present in the plant and the important bioactive constituents are the phenolics, flavonoids, alkaloids and tannins (Bellini et al., 2006). Plants have been known since antiquity to possess notable biological activities including antibacterial, antioxidative and anticancer properties. Secondary metabolites are potential anticancer drugs that 
cause either direct cytotoxicity on cancer cells or may affect processes involved in tumour development.

Tinospora cordifolia is a herbaceous vine indigenous to the tropical areas of India and Srilanka. It is called amrita, guduchi, shindikodi, giloy and so forth. The plant is used in indigenous system of medicine (Sivarajan and Balachandran, 1999) and the plant is known for its antipyretic, hypolipidemic, hypoglycemic, hepatoprotectivity, immunopotentiating and antineoplastic property (Singh et al., 2003; Jagetia and Rao, 2006 and Amita Mishra et al., 2013).

Aristolochia is the most diverse genus of Aristolochieaceae with about 120 species distributed throughout the tropics and subtropics and Aristolochia bracteolate Linn is a small glabrous shrub occurring in Nigeria, East Africa, Arabia and India (Burkill, 1985). This plant has been used against snake bite and scorpion stings, as antibiotics, antimalarial and aphrodisiac in Nigeria. Negi et al., (2003) reported that it is used as a gastric stimulant and in the management and treatment of cancer, lung inflammation and dysentery.

\section{In silico analysis}

With the identification of an increasing number of molecular targets associated with particular cancers, high throughput screening of compounds against a range of such targets now forms the basis of anti-cancer drug discovery. Examples are the cyclic-dependent kinases, which together with their cyclin partners, play a key role in the regulation of cell cycle progression, and inhibition of their activity delays or arrests progression of specific stages of the cell cycle. There are over 2000 kinases so far identified from genomic studies and all have a common site, the position where the ATP, that is, the source of the phosphate that is denoted, is bound (Newman et al., 2002). With the advent of proteomics and genomics, this problem can be partially alleviated with these efficient methods for rapid identification of protein targets of herbal ingredients (Dixon, 2001). Several bioinformatics tools and software have been used to develop efficient methods for facilitating target identification, as the first step in drug discovery (Shukla and Dixit, 2011)

Keeping in view the importance and advantages of combination chemotherapy using ethnoveterinary medicine on the tumour cells, this study is an attempt to explore the influence of 'combined effect of Aristolochia bracteolate and Tinospora cordifoliain using CADD (Computer Aided Drug Discovery) tools

\section{Materials and Methods}

\section{In silico analysis}

In silico research in medicine is thought to have the potential to speed the rate of discovery while reducing the need for expensive lab work and clinical trials. One way to achieve this is by producing and screening drug candidates more effectively. Here in this study the target protein for cancer was deduced based on previous literatures and the 3D structures of target proteins were downloaded from Protein Data Bank (PDB) and the drug like components were downloaded from chemical databases and were interacted with each other using a commercial tool- Discovery Studio software.

\section{Target preparation}

\section{Protein data bank}

The Protein Data Bank (PDB) is a repository for the 3-D structural data of large biological 
molecules such as proteins and nucleic acids. The data typically obtained by X-ray crystallography or NMR spectroscopy and submitted by biologists and biochemists from around the world, can be assessed at no charge on the internet. URL: http://www.rcsb.org/pdb

\section{NCBI}

The National Centre for Biotechnology Information (NCBI) advances science and health by providing access to biomedical and genomic information. It is an US government funded national resources for molecular biology information with access to many public databases and other references.

\section{Ligand preparation}

\section{Pubchem}

PUBChem is a database for chemical molecules. The system is maintained by the National Centre for Biotechnology Information (NCBI), a component of the National Library of Medicine, which is a part of the United States National Institutes of Health (NIH).

Pubchem can be accessed for free through a web user interface.

\section{Docking}

\section{Accelrys discovery studio}

Accelrys (NASDAQ: ACCL) is a software company headquartered in the US with representation in Europe and Japan. It provides software for chemical research especially in the areas of drug discovery and materials science.

Accelrys manages Nanotechnology Consortium producing software tools for rational nano-design

\section{Targeted proteins}

\section{PAI-1}

PLASMINOGEN ACTIVATOR inhibitor-1 (PAI-1) is a fast-acting inhibitor of tissue-type plasminogen activator and urokinase-type plasminogen activator. PAI-1 is a member of the serpin superfamily of protease inhibitors.

It is an important regulator of fibrinolysis and inhibits the activity of matrix metalloproteinases, which plays a crucial role in invasion of malignant cells across the basal lamina.

\section{PNA}

Peptide Nucleic Acids (PNA) have been used to inhibit transcription or translation of genes able to confer survival advantage to cancer cells such as c-myc and bcl-2. PNAs are useful tools for target directed anticancer therapeutic interventions.

\section{T6A}

3T6A is a C-Terminal domain of BCAR3 and its elevation in metastatic cancer patients indicates that it may be a more sensitive marker than previously studied modified nucleosides.

\section{Docking steps}

Docking study of the protein molecule and selected natural products were done using the Software Accelrys Discovery Studio.

The following steps were carried out according to the discovery studio module.

The protein molecule was imported Force Field applied to the molecule The binding cavities were detected Ligand molecule was imported 
Docking was performed by selecting drug molecule against the receptor site.

\section{Results and Discussion}

In silico analysis (Table 1-3)

\section{Proteins}

\section{Protein: PAI-1}

The structure of the PAI-1 protein is presented in Figure 3.

\section{Output}

Twelve poses were generated automatically by the Accelrys Discovery Studio, out of which poses the best docking score is noted. Results were saved automatically in the output file.

\section{Protein: 3PNA}

The structure of the target protein 3PNA has in total 2 chains. These are represented by 1 sequence-unique entity. The structure is shown in Figure 4.

\section{Output}

Ten poses were generated automatically by the Accelrys Discovery Studio, out of which poses the best docking score is noted. Results were saved automatically in the output file.

\section{Protein: 3T6A}

The structure of the target protein 3T6A is presented in the Figure 5.

\section{Output}

Forty one poses were generated automatically by the Accelrys Discovery Studio, out of which poses the best docking score was noted.

Results were saved automatically in the output file.

\section{Pharmacokinetic and pharmacodynamic analysis}

The pharmacokinetic analysis was carried out using PreADMET, a standard online tool and the results are given here under (Table 4-7)

Table.1 PAI -1 vs ligands at SITE 2

\begin{tabular}{|c|l|l|l|}
\hline S. No & \multicolumn{1}{|c|}{ Ligand } & \multicolumn{1}{c|}{ PMF } & \multicolumn{1}{c|}{ DOCKSCORE } \\
\hline 1. & Berberine & -5.73 & 10.525 \\
\hline 2. & Aristolochic acid & -20.90 & 89.20 \\
\hline
\end{tabular}

Table.2 3PNA SITE 4

\begin{tabular}{|c|l|c|c|}
\hline S. No & \multicolumn{1}{|c|}{ Ligand } & \multicolumn{1}{c|}{ PMF } & DOCKSCORE \\
\hline 1. & Berberine & -57.48 & 40.522 \\
\hline 3. & Aristolochic acid & -69.31 & 38.828 \\
\hline
\end{tabular}

Table.3 3T6A vs Berberine and Aristolochic acid at site 4

\begin{tabular}{|c|l|c|l|l|}
\hline S. No & \multicolumn{1}{|c|}{ Ligand } & PMF & DOCKSCORE & LIGAND ENERGY \\
\hline 1. & Berberine & -69.22 & 62.54 & -0.333 \\
\hline 2. & Aristolochic acid & -83.19 & 65.49 & -0.249 \\
\hline
\end{tabular}


Table.4 Pharmacokinetic properties of Berberine

\begin{tabular}{|l|r|}
\hline ID & Value \\
\hline BBB & 0.460155 \\
\hline Buffer_solubility_mg_L & 5.86471 \\
\hline Caco2 & 20.9811 \\
\hline CYP_2C19_inhibition & Non \\
\hline CYP_2C9_inhibition & Inhibitor \\
\hline CYP_2D6_inhibition & Non \\
\hline CYP_2D6_substrate & Non \\
\hline CYP_3A4_inhibition & Non \\
\hline CYP_3A4_substrate & Weakly \\
\hline HIA & 96.082544 \\
\hline MDCK & 79.0183 \\
\hline Pgp_inhibition & Inhibitor \\
\hline Plasma_Protein_Binding & 96.839504 \\
\hline Pure_water_solubility_mg_L & 0.10746 \\
\hline Skin_Permeability & -3.77482 \\
\hline SKlogD_value & 2.65387 \\
\hline SKlogP_value & 3.90187 \\
\hline SKlogS_buffer & -4.76486 \\
\hline SKlogS_pure & -6.50186 \\
\hline
\end{tabular}

Table.5 Pharmacokinetic properties of Aristolochic acid

\begin{tabular}{|l|}
\hline ID \\
\hline BBB \\
\hline Buffer_solubility_mg_L \\
\hline Caco2 \\
\hline CYP_2C19_inhibition \\
\hline CYP_2C9_inhibition \\
\hline CYP_2D6_inhibition \\
\hline CYP_2D6_substrate \\
\hline CYP_3A4_inhibition \\
\hline CYP_3A4_substrate \\
\hline HIA \\
\hline MDCK \\
\hline Pgp_inhibition \\
\hline Plasma_Protein_Binding \\
\hline Pure_water_solubility_mg_L \\
\hline Skin_Permeability \\
\hline SKlogD_value \\
\hline SKlogP_value \\
\hline SKlogS_buffer \\
\hline SKlogS_pure \\
\hline
\end{tabular}

\begin{tabular}{|c|}
\hline Value \\
\hline 0.693196 \\
\hline 8.01923 \\
\hline 55.5786 \\
\hline Inhibitor \\
\hline Inhibitor \\
\hline Inhibitor \\
\hline Substrate \\
\hline Inhibitor \\
\hline Substrate \\
\hline 97.884641 \\
\hline 14.4092 \\
\hline Inhibitor \\
\hline 98.54205 \\
\hline 3.30745 \\
\hline-4.37318 \\
\hline 0.392330 \\
\hline 0.392330 \\
\hline-4.62268 \\
\hline-5.00732 \\
\hline
\end{tabular}


Table.6 Pharmacodynamic properties of Berberine

\begin{tabular}{|c|c|c|}
\hline $\mathbf{P a}$ & $\mathbf{P i}$ & Activity name \\
\hline 0,920 & 0,003 & Gluconate 2-dehydrogenase (acceptor) inhibitor \\
\hline 0,914 & 0,005 & Aspulvinone dimethylallyltransferase inhibitor \\
\hline 0,910 & 0,005 & 5 Hydroxytryptamine release stimulant \\
\hline 0,906 & 0,003 & Linoleate diol synthase inhibitor \\
\hline 0,883 & 0,005 & Mucomembranous protector \\
\hline 0,869 & 0,004 & JAK2 expression inhibitor \\
\hline 0,867 & 0,004 & Fibrinolytic \\
\hline 0,868 & 0,009 & Chlordecone reductase inhibitor \\
\hline 0,864 & 0,006 & Feruloyl esterase inhibitor \\
\hline 0,853 & 0,003 & Platelet derived growth factor receptor kinase inhibitor \\
\hline 0,843 & 0,002 & Steroid N-acetylglucosaminyltransferase inhibitor \\
\hline 0,841 & 0,003 & Preneoplastic conditions treatment \\
\hline 0,849 & 0,024 & CYP2C12 substrate \\
\hline 0,822 & 0,003 & MMP9 expression inhibitor \\
\hline 0,828 & 0,023 & Ubiquinol-cytochrome-c reductase inhibitor \\
\hline 0,796 & 0,004 & Antimutagenic \\
\hline
\end{tabular}

Table.7 Pharmacodynamic properties of Aristolochic acid

\begin{tabular}{|c|c|c|}
\hline $\mathbf{P a}$ & $\mathbf{P i}$ & Activity name \\
\hline $\mathbf{0 , 9 9 8}$ & 0,000 & Inflammatory Bowel disease treatment \\
\hline $\mathbf{0 , 9 9 8}$ & 0,001 & Platelet antagonist \\
\hline $\mathbf{0 , 9 9 7}$ & 0,001 & Atherosclerosis treatment \\
\hline $\mathbf{0 , 9 9 6}$ & 0,000 & Antioxidant \\
\hline $\mathbf{0 , 9 9 7}$ & 0,001 & Lipoprotein disorders treatment \\
\hline $\mathbf{0 , 9 9 6}$ & 0,001 & Platelet aggregation inhibitor \\
\hline $\mathbf{0 , 9 9 5}$ & 0,001 & Antileukemic \\
\hline $\mathbf{0 , 9 9 6}$ & 0,002 & Antidiabetic \\
\hline $\mathbf{0 , 9 8 6}$ & 0,004 & Antineoplastic \\
\hline
\end{tabular}

Fig.1 Tinospora cordifolia

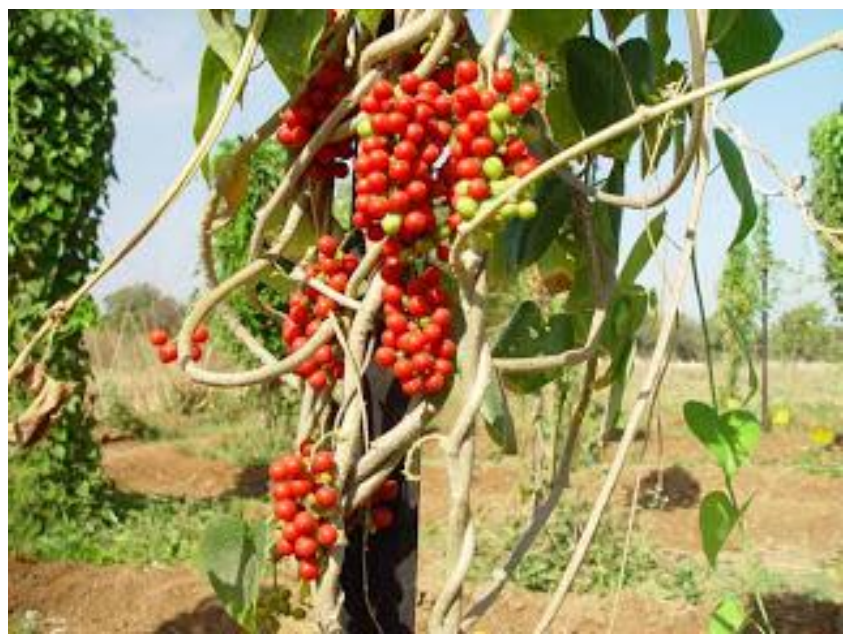

Photo courtesy: http:///www. http://www.indiamart.com 
Fig.2 Aristolochia bracteolate

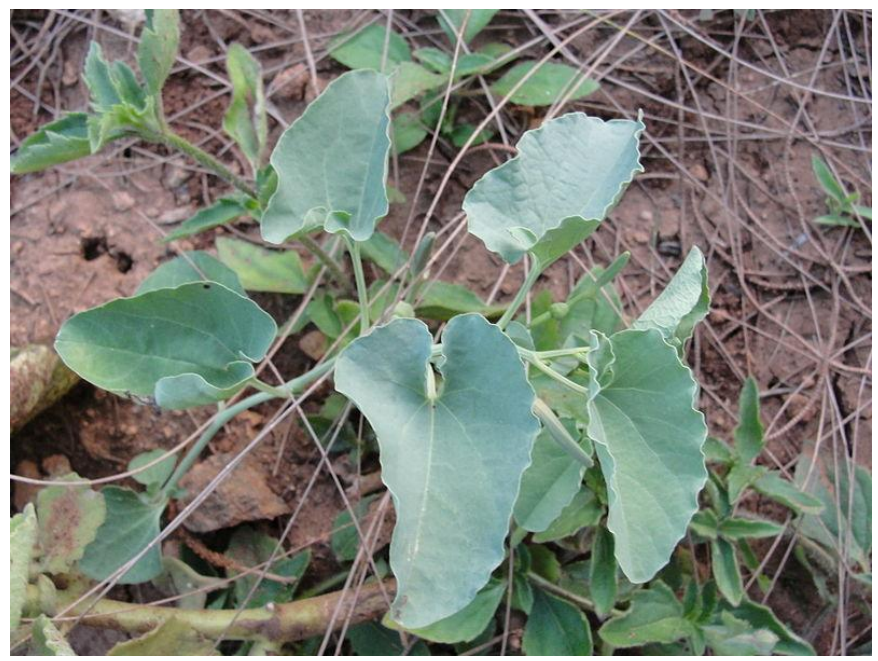

Photo courtesy: http:///www. http://tropical.theferns.info/

Fig.3 The structure of the target protein plasminogen activator inhibitor-1 (PAI-1)

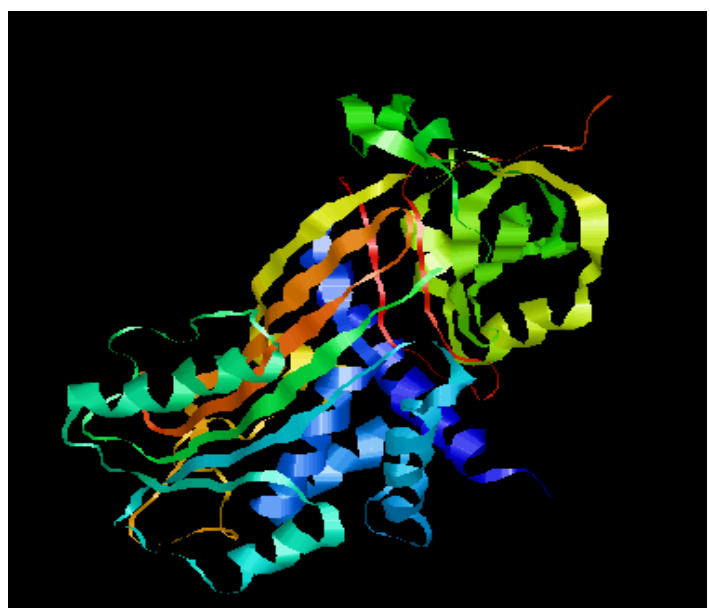

Fig.4 The structure target protein Peptide Nucleic Acids (3PNA)

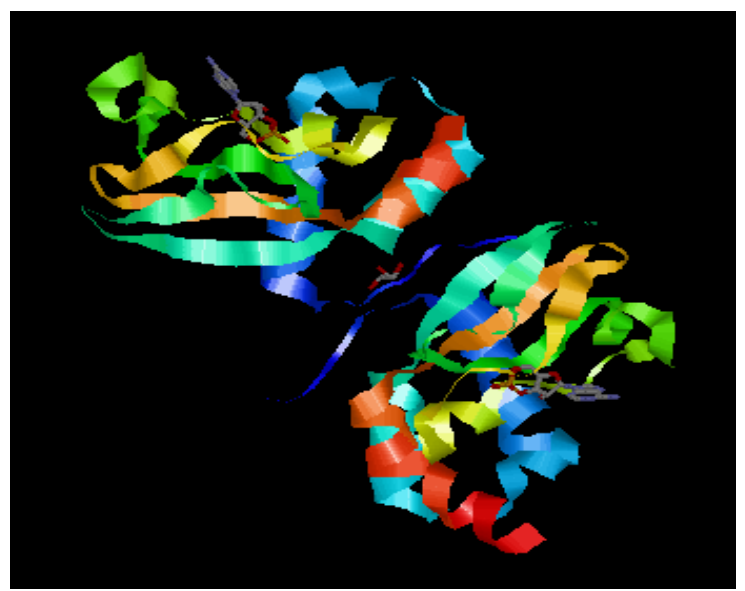


Fig.5 The structure of the C-terminal domain from the novel SH2-containing protein BCAR3. (3T6A)

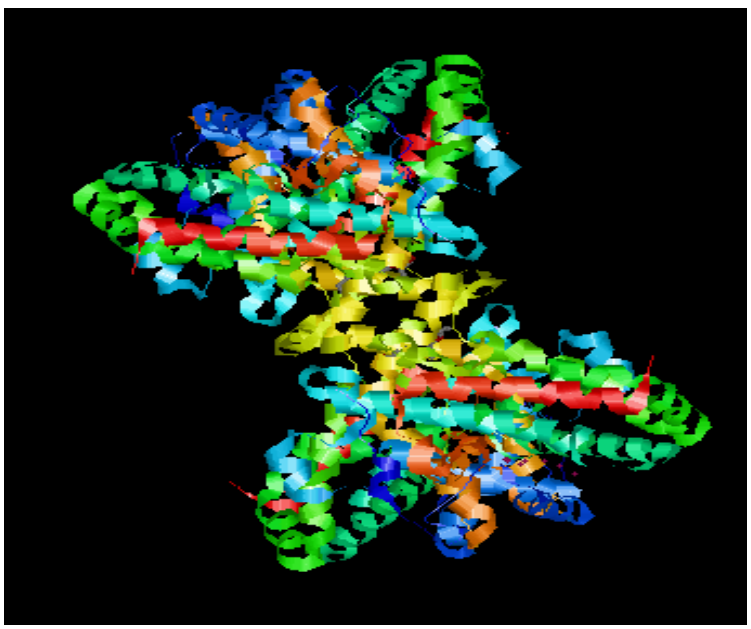

Active principles from Tinospora cordifolia and Aristolochia bracteolate

Fig.6 The structure of berberine<smiles>COc1ccc2cc3[n+](cc2c1OC)CCc1cc2c(cc1-3)OCO2</smiles>

Berberine (Tinospora cordifolia)

Fig.7 The structure of Aristolochic acid<smiles>COc1cccc2c1cc([N+](=O)[O-])c1c(C(=O)O)cc3c(c12)OCO3</smiles>

Aristolochic acid (Aristolochia bracteolate) 
Fig.8 Interaction results of PAI-1

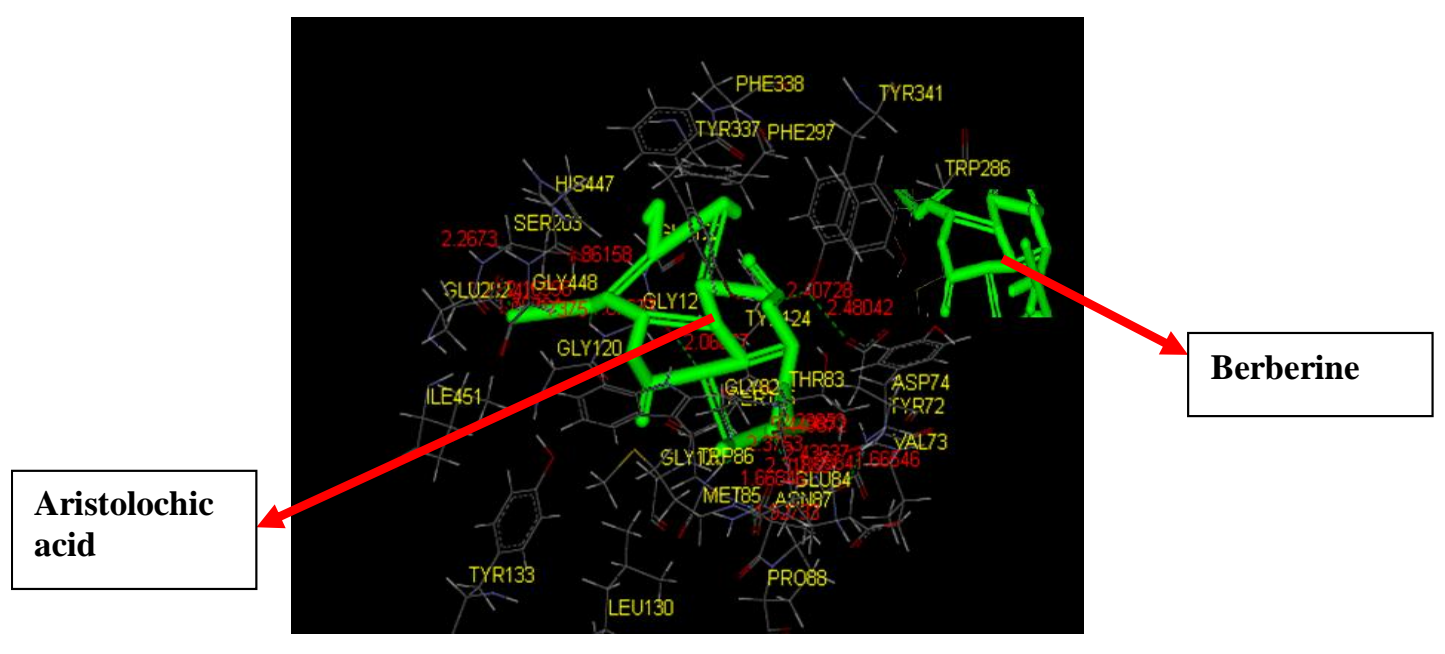

Fig.9 Interaction results of 3PNA

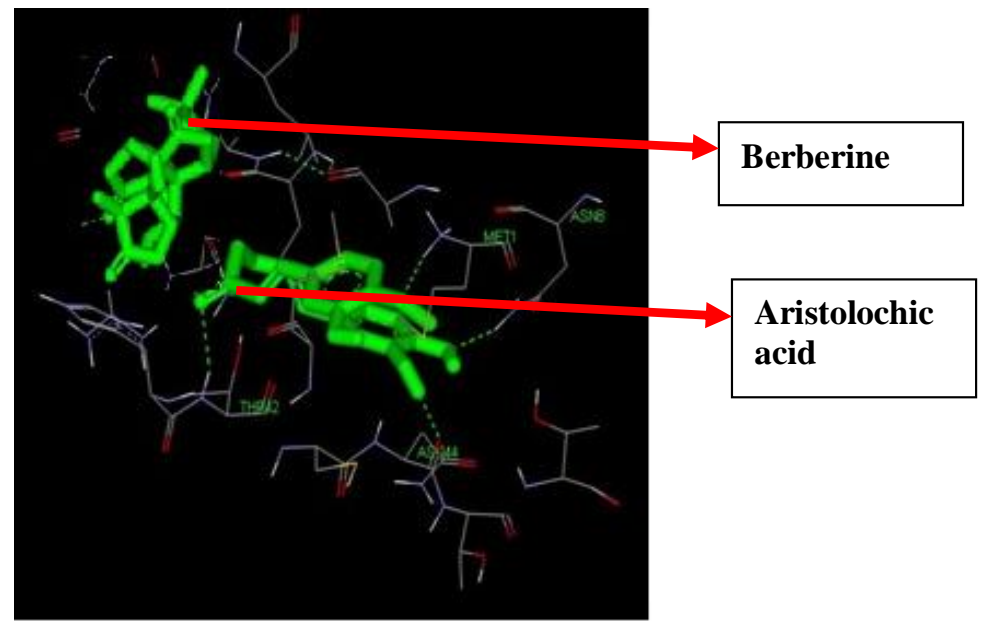

Fig.10 The structure of the target protein 3T6A

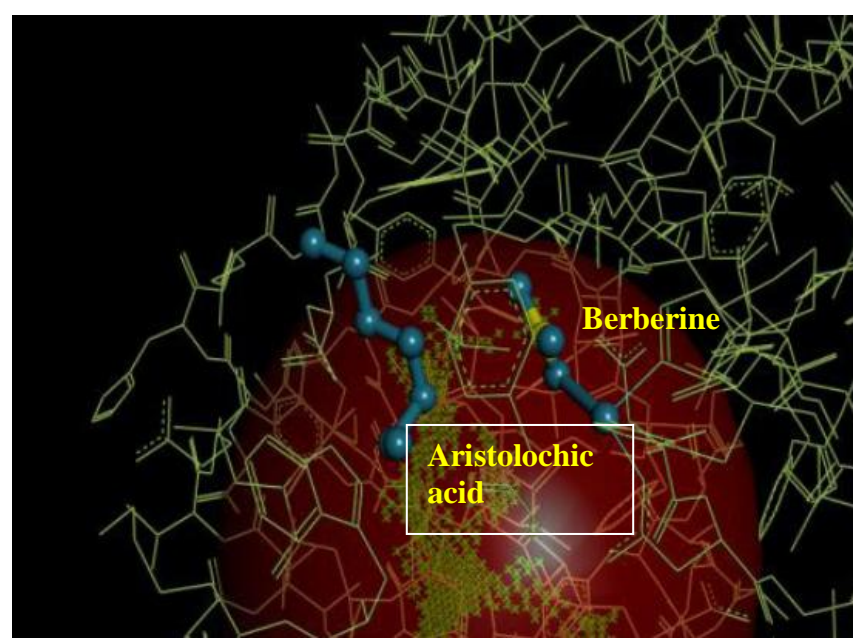




\section{Pharmacodynamic properties}

The Pharmacodynamic analysis was carried out using PASS on line server and the results are depicted hereunder (Table 6 and 7).

\section{In silico analysis}

The results of virtual screening of EVP phytochemicals berberine - CID 2353 (Tinospora cordifolia) and aristolochic acid CID 2236 (Aristolochia bracteolata) showed the predicted binding affinity towards the binding site (Fig. 6 and 7). The EVP phytochemicals were further docked to confirm the effective interaction with the cancer target proteins Plasminogen Activator Inhibitor - 1(PAI-1, Peptide Nucleic Acids (3PNA) and Modified Adenosine nucleotide (3T6A) using Accelyrs Discovery Studio.

Totally three different target groups were selected in this study to analyze the phytoprinciples having anti cancerous activity. Amount the three target groups, 3T6A (C-terminal of BCAR-3) was found to be the effective target against cancer interacting with Aristolochic acid with a highest dock score of 65.492 and the free potential energy (PMF) value of 69 indicating their potential anticancer activities.

Both the compounds taken for the study possess very good pharmacokinetic and Pharmacodynamic properties. Further studies are needed in experimental models to confirm their anti-cancer potency (Fig. 8-10).

Cancer is an imminent global disaster and the incidence of cancer is widespread in animals with malignant characters and lesions like human beings. The herbal based natural products used in Ethnoveterinary practices (EVP) may present a cost effective, affordable and sustainable alternative to synthetic medicines used in the treatment of cancer.
Aristolochia bracteolate and Tinospora cordiflora are medicinal plants of India used in traditional medicine system and ethnoveterinary practices. Keeping in view the importance and advantages of combination chemotherapy using herbal based natural EVP products on the tumour cells, this study is an attempt to explore the influence of 'combined extracts of Aristolochia bracteolata and Tinospora cordiflora' using in silico analysis with Accelyrs Discovery Studio. Further the plant extracts were used in experimentally induced carcinogenesis in invitro models for their anticancer properties.

From the in silico analysis, it is evident that the combination of Aristolochia bracteolate and Tinospora cordiflora have shown to possess significant anti-proliferative and antiapoptotic properties. Most of these compound work synergistically and hence, the combined extracts or whole plant may be a promising drug entity to enter the evidence based therapeutics for cancer.

\section{Acknowledgement}

The authors wish to thank the Tamilnadu Veterinary and Animal Sciences University for their support in carrying out this study.

\section{References}

Ahmedin Jemal, Freddie Bray, M. Melissa, Jacques Ferlay, Elizabeth ward and David Forman (2011) Global cancer statistics. CA: A Cancer Journal for Clinician 61 (2): 69-90

Amita Mishra, Shashank Kumar and Abhay K. Pandey (2013) Scientific validation of the medicinal efficacy of Tinospora cordifolia. Scientific World Journal: 112

Baade, P.D., D.R. Youlden and L.J. Krnjacki (2009) International epidemiology of 
prostate cancer; geographical distribution and secular trends. Mol Nutr Food Res. 53: 171- 184

Bellini, M.F., J.P.F. Angeli, R. Matuo, A.P. Terezan, L.R. Ribeiro and M.S. Mantovani (2006) Antigenotoxicity of blazei mushroom organic and aqueous extracts in chromosomal abrerration and cytokinesis block in assays in $\mathrm{CHO}-\mathrm{kI}$ and HTC cells Toxicology in vitro 20 (3): 355-360

Burkill HM (1985) The useful plants of West Tropical Africa. $2^{\text {nd }}$ edition. Vol I. Royal Botanic Gardens Kew. Families A-D. Pp215

Center, M.M., A. Jemal and E. Ward (2009) International trends in colorectal cancer incidence rates. Cancer Epidemiol Biomarkers Prev. 18: 1688- 1694

Center, M.M., A. Jemal, R.A. Smilth and E. Ward (2009a) Worldwide variation in colorectal cancer. CA Cancer J Clin 59: 366- 378

Charka, Charaka Samhita, Part I \& II, (Hindi commentary by Pandey \& Chaturvedi), edited by Rajeshwar Datta Shastri et al., (Chaukhambha Vidyabhawan, Varanasi), 1961.

Cichewitz, R.H and S.A. Kouzi (2004) Chemistry, biological activity and chemotherapeutic potential of betulinic acid for the prevention and treatment of cancer and HIV infection. Med Res Rev 24:90 - 114

Cragg, G.M and D.J. Newman (2005) Plants as source of anticancer agents. $J$ Ethnopharmacol 100: 72 -79

Ezzati, M and A.D. Lopez (2003) Estimates of global mortality attributable to smoking in 2000.Lancet 362: 847- 852

Ezzati, M., S.J. Henley, A.D. Lopez and M.J. Thun (2005) Role of smoking in global and regional cancer epidemiology: current patterns and data needs. Int $J$ Cancer 116: 963-971
Jagetia, G.C and S.K. Rao (2006) Evaluation of the antineoplastic activity of guduchi (Tinosporacordifolia) ascites carcinoma bearing mice. Biological and Pharmaceutical Bulletin 29 (3): 460466

Kasibhatla, S. and B. Tseng (2003) Why target Apoptosis in Cancer treatment? Mol Cancer Ther. 2: 573- 580

Kirti Sinha, N.P. Mishra, J. Singh and S.P.S. Khanuja (2004) Tinosporacordifolia (Guduchi), a reservoir plant for therapeutic applications: A Review. Indian Journal of Traditional Knowledge 3 (3): 257-270

Kvale, R., A. Auvinenadn H.O. Adami (2007) Interpreting trends in prostate cancer incidence and mortality in the five Nordic countries. J Nati Cancer Inst. 99: 1881-1887

Negi, P. S., C. Anandharamakrishnan and G.K. Jayaprakasha (2003) Antibacterial activity of Aristolochia bracteolate roots extracts. J Med Food (6): 401-410

Newman, D.J., G.M. Cragg, S. Holbeck and E.A. Sausville (2002) Natural products as leads to cell cycle pathway targets in cancer chemotherapy. Current Cancer Drug Targets 2: 279 -308

Ping-Chung Kuo, Yue-Chiun Li and TianShungWu (2012) Chemical constituents and pharmacology of the Aristolochia species. J Tradit Complement Med 2 (4) $249-266$

Sankaranarayanan, R., B.M. Nene and S.S. Shastri (2009) HPV screening for cervical cancer in rural India. $N$ Engl $J$ Med 360: 1385 -1394

Sapna Mishra, Peeyush kumar and Anushree Malik (2013) Effect of process parameters on the enzyme activity of a novel Beaweria bassiana isolate. Int.J.Curr.Microbiol.App.Sci 2 (9): 4956

Sausville, E.A., D. Zaharevitz, R. Gussio, L. Meijer, M. Louaro- Leost C. Kunick 
and S.G. Arbuck (1999) Cyclindependent kinases: initial approaches to exploit a novel therapeutic target. Pharmacology \& Therapeutics 82: 285

Sherris, J., S. Wittet and A. Kleine (2009) Evidence based alternative cervical cancer screening approach in low resource settings. In Perspect Sex Reprod Health 35:147- 154

Shobana Chandrasekar, Sumathi Thangarajan, Sujatha Loganathan, (2013) Molecular docking studies of Bacoside-A, an active component of Bacopa monniera with DJ1 for Anti-Parkinson's drug design. Biomirror: 44-48

Singh, S.S., S.C. Pandey, S. Srivastasa, V.S. Gupta, B. Patro and A.C. Ghosh. (2003) Chemistry and medicinal properties of Tinosporacordiflora (Guduchi) Indian Journal of Pharmacology 35(2): 83- 91

Sivarajan, V.V. and I. Balachandran (1999) Ayurvedic Drugs and Their plants Sources. IBH Publishing, New Delhi, India

Sujatha, P L, Preetha S P and Kumarasamy P (2015), Rapid Vaccine Identification in microbial genomics - an in-silico approach with special reference to Chikungunya virus. International Journal of Scientific Research and Engineering Studies. 2(8): 34: 46

Sushruta, Sushruta Samhita, commentary by Dalhana, edited by Jadvji Trikamji Acharya, (Chaukhambha Orientalia, Varanasi \& Delhi) 1992.

Thakur, R.S., H.S. Puri and Akhtar Hussain (1989) Major Medicinal Plants of India (Central Institute of Medicinal and Aromatic Plants, Lucknow).pp.499.

Thirumal, M., R. Vadivelan, G. Kishore and V.S. Brahmaji (2012) Aristolochia bracteolate: An overview on pharmacognostical, phytochemical and pharmacological properties. Earth Journal 1 (1) 70- 82

Thomas G. Cotter (2009) Apoptosis and Cancer: the genesis of a research field. Nature Reviews Cancer 9: 501- 507

WHO-World Health Organisation: The global burden of disease: 2004 Update. Geneva. World Health Organisation; 2008

\section{How to cite this article:}

Cecilia Joseph, S. Preetha, P.L. Sujatha, C. Balachandran and Punniamurthy, N. 2018. An Evaluation of the Anti-Cancerous Effects of Tinospora cordifolia and Aristolochia bracteolate Using CADD (Computer Aided Drug Discovery) Tools. Int.J.Curr.Microbiol.App.Sci. 7(06): 722-733. doi: https://doi.org/10.20546/ijcmas.2018.706.085 